\title{
Nosocomial infection program
}

\author{
SHIRLEY PATON MN RN
}

$\mathrm{N}$ OSOCOMIAL INFECTION ACTIVITIES AT THE LABORATORY CENtre for Disease Control (LCDC) focus on the prevention and control of infectious diseases that are spread in the context of health care delivery in the home, community or health care facility. Nosocomial infections comprise those infections that are transmitted from patient to patient, from patient to health care worker, from health care worker to patient, from medical and surgical instruments to patient and from the environment to patient.

Nosocomial infections can result in increased morbidity, prolonged hospitalization, temporary and permanent dysfunction and even death. Because no national, provincial or regional programs have comprehensive databases on the incidence or prevalence of nosocomial infections in Canada, the magnitude, scope and associated costs must be extrapolated from data generated in other countries.

Thirteen per cent of the Canadian population $(3,610,817)$ were admitted to hospital in 1991, according to Statistics Canada. Based on data extrapolated from the United States (1), 5 to $10 \%(180,540$ to 361,082 patients) likely acquired a nosocomial infection. Of these, $25 \%$ had surgical wound infections, $10 \%$ had pneumonia, $42 \%$ had urinary tract infections, $5 \%$ had bacteremias, and the remaining $19 \%$ had other nosocomial infections.

The cost to the Canadian health care system for nosocomial infections is also unknown. In the United States, conservative estimates (2) for the average extra charges per nosocomial infection for 1992 were: surgical sites, us $\$ 3,152$; pneumonia, us $\$ 5,683$; bacteremia, us $\$ 3,517$; urinary tract infections, us $\$ 680$; and other sites, US\$1,617. This results in an

Bureau of Communicable Disease Epidemiology, Laboratory Centre for Disease Control, Ottawa, Ontario

Correspondence: Shirley Paton, Bureau of Communicable Disease Epidemiology, Laboratory Centre for Disease Control, 1712 Jeanne Mance Building, Tunney's Pasture, Ottawa, Ontario K2A OL2. Telephone (613) 957-0326, Fax (613) 952-6668, e-mail Spaton@HPB.HCW.ca average cost per nosocomial infection of US $\$ 2,100$ or a total of us $\$ 4,532,000,000$ per annum.

\section{NOSOCOMIAL INFECTIONS AND THE BUREAU OF COMMUNICABLE DISEASE EPIDEMIOLOGY}

In 1980, the LCDC established the Bureau of Infection Control in response to a growing demand for infection control resources at the national level. The bureau was subsequently reorganized and became the Division of Infection Control within the Bureau of Communicable Disease Epidemiology (BCDE).

Over its 15-year history, the division has established a number of programs to assist infection control personnel and to monitor the incidence and prevalence of nosocomial infections. These have included education programs for new infection control practitioners, development of the Infection Control Guideline series and establishment of the Canadian Nosocomial Infection Surveillance Program (CNISP). Recommendations from a 1993 ad hoc committee on emerging infectious diseases issues reiterated the need for a comprehensive national strategy on nosocomial infections and antimicrobial resistance (3).

\section{CANADIAN NOSOCOMIAL INFECTION SURVEILLANCE PROGRAM}

The Bureau of Infection Control initiated the CNISP in June 1984. A summary of the results from June 1984 to May 1985 has been published (4).

In 1993, the BCDE began the establishment of a sentinel hospital network that will form the basic data collection unit in the CNISP. A meeting was held with BCDE and the Canadian Hospital Epidemiology Committee (CHEC), a subcommittee of the Canadian Infectious Disease Society, to formulate the structure and role of a jointly organized sentinel hospital network. Eighteen acute care facilities from 10 provinces have agreed to participate in the network.

CNISP has three major goals: first, to collect and analyze surveillance data from the sentinel hospital network to provide a valid estimation of the magnitude, type and cost of noso- 
comial infections in Canadian health care facilities; second, to analyze and report nosocomial infection data to identify regional and national trends in nosocomial infection rates, antimicrobial resistance and nosocomial pathogens; and third, to provide health care facilities with comparative data on nosocomial infections in different patient populations.

The first CNISP study, using the sentinel hospital network, was initiated January 1, 1995. The objectives of the study are: first, to characterize nosocomially acquired methicillinresistant Staphylococcus aureus (MRSA) in Canadian health care facilities; and second, to evaluate the effectiveness of prevention and control techniques currently employed. A questionnaire was developed and is being tested; data collection will begin April 1, 1995. A second study is under development that will identify and monitor national trends in surgical wound infections. Future studies will examine the role of Clostridium difficile in nosocomial infections and explore the significance of nosocomial infections associated with central intravascular lines.

\section{ANTIMICROBIAL DRUG RESISTANCE}

The consequences of antimicrobial drug resistance are profound and measurable. Whether the resistant organisms are Gram-negative bacilli, Gram-positive cocci or fungi, health care settings are faced with patients who have been colonized or infected with resistant organisms while undergoing treatment. Occasionally, these patients have acquired the resistant organism while receiving care in another setting, sometimes in another part of the world. These patients represent a reservoir of resistant infectious organisms. In one case, a patient from the Punjab was colonized with MRSA. This patient was the source of a MRSA outbreak that spread from Mission, British Columbia through Vancouver to Winnipeg and on to northern Manitoba (5). Changing antibiotic resistance patterns that lead to costly and complex treatment regimens are placing local regional and national infection control programs under increasing pressure to introduce protocols to decrease the risk of nosocomial transmission.

The CNISP will analyze and report trends in the resistance patterns of antimicrobial-resistant nosocomial pathogens (eg, an MRSA study to begin April 1995). This analysis may be used to identify effective and timely activities to prevent and control the spread of antimicrobial-resistant organisms within and between health care facilities.

\section{NOSOCOMIAL INFECTIONS AND THE NATIONAL LABORATORY}

For many years, the Bureau of Microbiology has provided traditional diagnostic services in support of outbreak investigations in nosocomial settings. These activities have been in collaboration with provincial laboratories and the combined National Laboratory for Bacteriology and Enteric Pathogens and have drawn on available long standing expertise and experience in phenotypic identification.

Recently, a DNA Core Facility was established. Scientists and technologists have been instrumental in the development and introduction of a wide spectrum of genetically based tech- nologies that now form a major component of our specialized diagnostic services. These methodologies are available to all national laboratories in the bureau and are being applied in studies related to nosocomial acquisition and spread of bacterial pathogens. Molecular subtyping methods are essential for effective monitoring of spread of nosocomial pathogens between individuals. Additionally, they are very helpful in establishing the dynamics of community subepidemics, clonal spread and the emergence of new genetic variants.

Related projects in the National Laboratory for Bacteriology and Enteric Pathogens involve phenotypic and genotypic characterization of methicillin-resistant staphylococci, Legionella species, Escherichia coli, multidrug-resistant Mycobacterium tuberculosis, Stenotrophomonas maltophilia, Pseudomonas aeruginosa, Burkholderia cepacia and $C$ difficile. The Bureau of Microbiology anticipates supporting a strengthened initiative in nosocomial infections through a laboratory program designed to address recently recognized agents and facilitate participation in the CNISP.

\section{INFECTION CONTROL GUIDELINES}

The Infection Control Guideline series, produced by BCDE, address infection control activities that may take place within health care facilities or other settings where health care is delivered.

The Infection Control Guidelines are developed under the direction of the National Steering Committee on Infection Control Guidelines, whose membership includes infection control practitioners, hospital epidemiologists, infectious disease physicians and medical microbiologists. The steering committee establishes the series' priorities and works closely with ad hoc working groups to develop practical infection control guidelines.

The Infection Control Guideline series includes isolation and precaution techniques (6), occupational health in health care facilities (7), perinatal care (8), organization of hospital infection control programs (9), antimicrobial use in health care facilities (10), long term care facilities (11), and a compilation of parts I to V - Prevention of Intravascular Infections, Prevention of Surgical Wound Infections, Prevention of Nosocomial Pneumonia, Prevention of Urinary Tract Infections and Hospital Environmental Controls. Two of these, Prevention of Intravascular Infections and Hospital Environmental Controls, are under revision. The Infection Control Guidelines are published and distributed on a cost recovery basis through Canada Communication Group (telephone [819] 956-4802). Costs for individual guidelines range from $\$ 9.95$ to $\$ 12.95$.

Beginning in December 1991, a series of meetings was organized by BCDE to develop recommendations entitled "Bloodborne Pathogens in the Health Care Setting: Risk for Transmission" (13). Participants recommended the development of consistent national recommendations on the prevention of bloodborne pathogen transmission applicable to a broad spectrum of health care agencies. In 1994, the Steering Committee on Infection Control Guidelines accepted this task and has initiated work on a comprehensive document entitled "Preventing Bloodborne Pathogen Transmission in Health 
Care Settings". It is anticipated that it will be released in the summer of 1995.

\section{SUMMARY}

The Nosocomial Infection Program at LCDC has developed and expanded over the past two decades. The Infection Control Guidelines series has assisted health care professionals in improving the quality of care provided in health care facilities across Canada. With its expanding mandate, the Nosocomial Infection Program in partnership with CHEC and other infection control practitioners is developing a comprehensive strategy for nosocomial infection surveillance, including the evaluation of drug-resistant organisms.

\section{REFERENCES}

1. Haley RW, Culver DH, White JW, Morgan WM, Emori TG. The nationwide nosocomial infection rate: a need for vital statistics. Am J Epidemiol 1985;121:159-67.

2. Martone WJ, Jarvis WR, Culver DH, Haley RW. Incidence and nature of endemic and epidemic nosocomial infections. In: Bennett JV, Brachman PS, eds. Hospital Infections, 3rd edn. Toronto: Little, Brown and Company, 1992:592-3.

3. Laboratory Centre for Disease Control. Proceedings and recommendations of the expert working group on emerging infectious disease issues. Can Commun Dis Rep 1994;20(Suppl 2):1-21.

4. Health and Welfare Canada. Canadian nosocomial infection surveillance program: annual summary. Can Dis Wkly Rep 1986;12(Suppl 1):1-25.

5. Roman RS, Smith J, Walker M, et al. Rapid geographic spread of an MRSA strain. Clin Infect Dis 1994;19:588. (Abst 148)

6. Health and Welfare Canada. Infection Control Guidelines For Isolation and Precaution Techniques. Ottawa: Department of National Health and Welfare, 1992. (Supply and Services Canada, Cat no H30-111-6-1E[1F])

7. Health and Welfare Canada. Infection Control Guidelines For Occupational Health in Health Care Facilities. Ottawa: Department of National Health and Welfare, 1990. (Supply and Services Canada, Cat no H30-111-6-2E[2F])

8. Health and Welfare Canada. Infection Control Guidelines For Perinatal Care. Ottawa: Department of National Health and Welfare, 1988. (Supply and Services Canada, Cat no $\mathrm{H} 30-111-6-3 \mathrm{E}[3 \mathrm{~F}])$

9. Health and Welfare Canada. Infection Control Guidelines For Organization of Hospital Infection Control Programs. Ottawa: Department of National Health and Welfare, 1990. (Supply and Services Canada, Cat no H30-111-6-5E[5F])

10. Health and Welfare Canada. Infection Control Guidelines For Antimicrobial Utilization in Health Care Facilities. Ottawa: Department of National Health and Welfare, 1990. (Supply and Services Canada, Cat no H30-111-6-7E[7F])

11. Health and Welfare Canada. Infection Control Guidelines For Long Term Care Facilities. Ottawa: Department of National Health and Welfare, 1994. (Supply and Services Canada, Cat no H30-111-6-6E[6F])

12. Health and Welfare Canada. Infection Control Guidelines: Parts I-V. Ottawa: Department of National Health and Welfare, 1990. (Supply and Services Canada, Cat no H30-111-6-4E[4F])

13. Laboratory Centre for Disease Control. Bloodborne pathogens in the health-care setting: risk for transmission. Can Dis Wkly Rep 1992;18:177-84. 


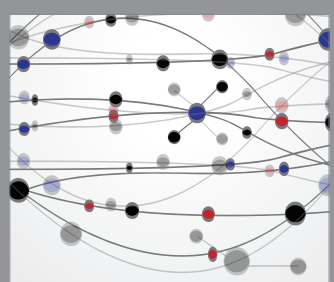

The Scientific World Journal
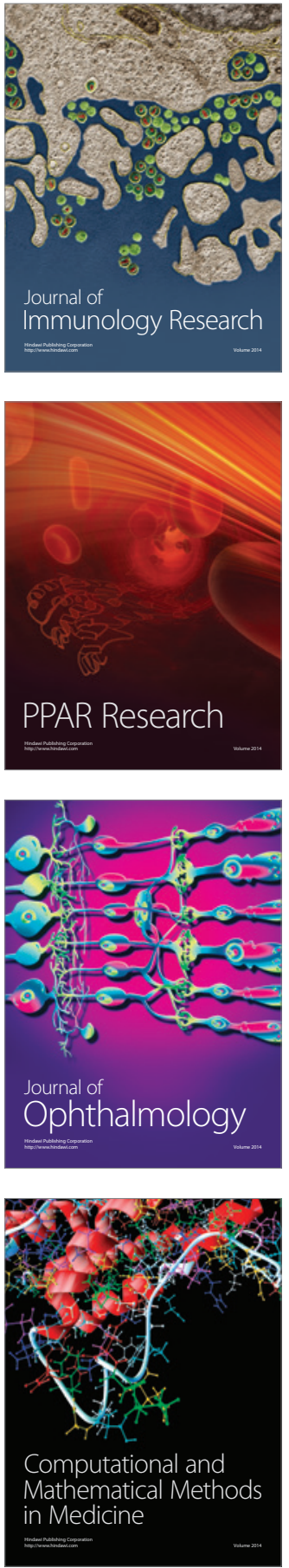

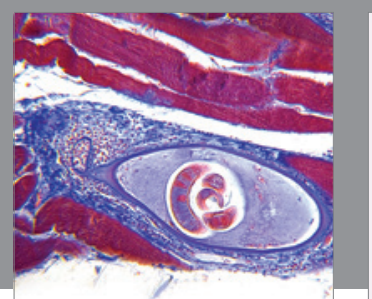

Gastroenterology Research and Practice

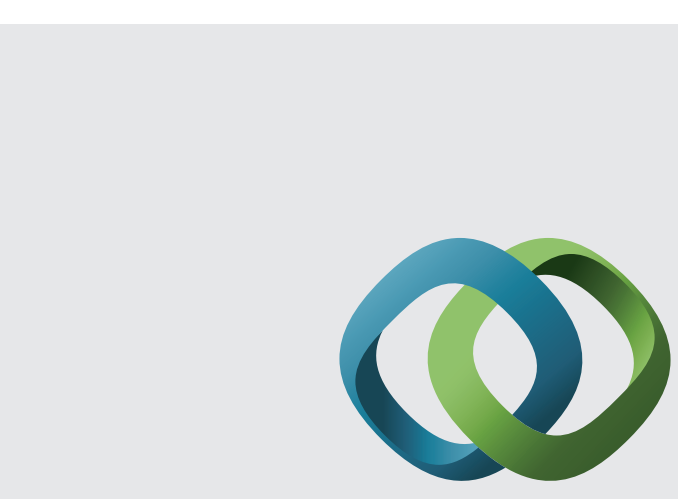

\section{Hindawi}

Submit your manuscripts at

http://www.hindawi.com
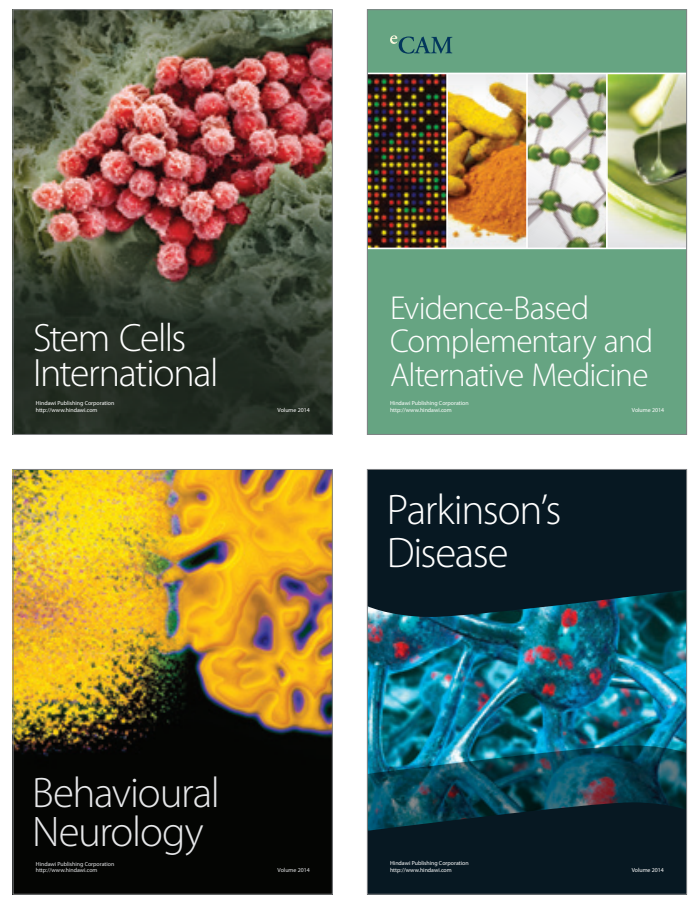
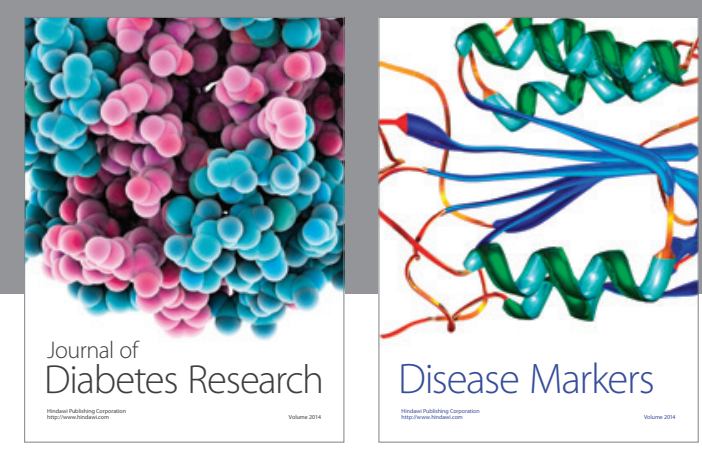

Disease Markers
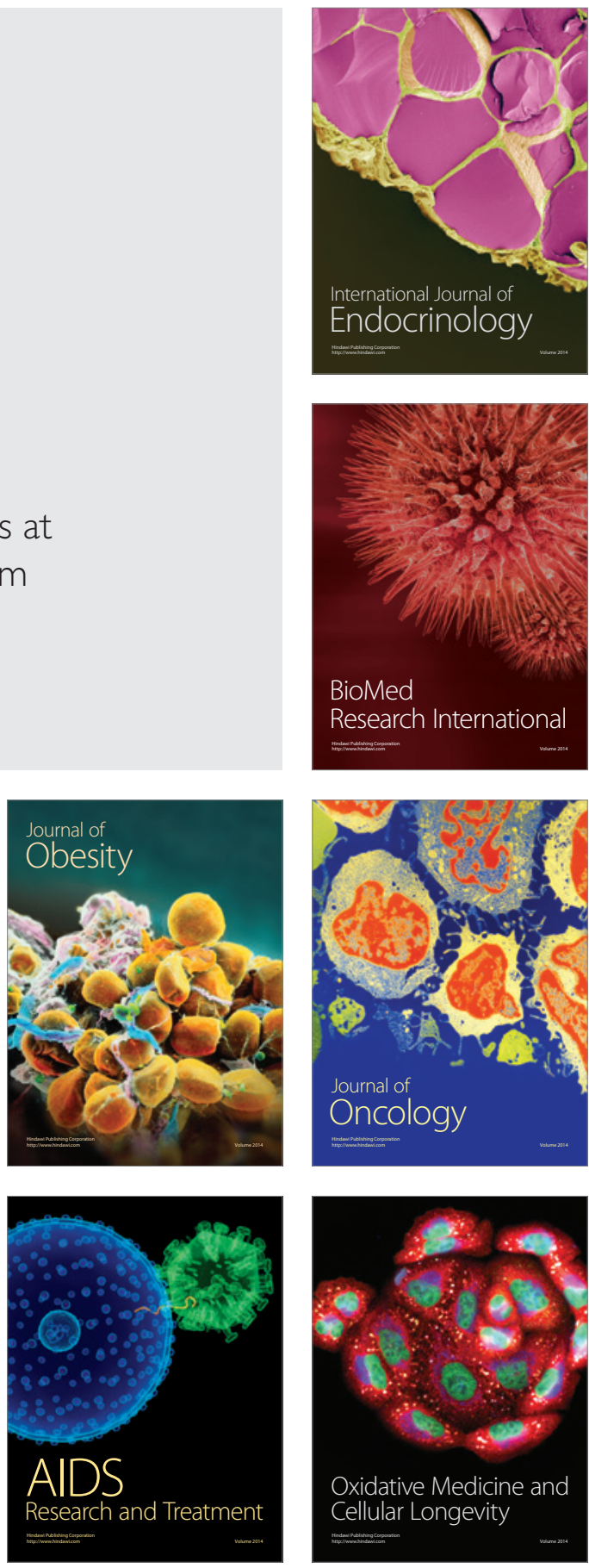